\title{
Low polymorphisms in pfact, pfugt and pfcarl genes in African Plasmodium falciparum isolates and absence of association with susceptibility to common anti-malarial drugs
}

Francis Tsombeng Foguim ${ }^{1,2,3}$, Marie Gladys Robert1,2,3, Mamadou Wagué Gueye ${ }^{4}$, Mathieu Gendrot ${ }^{1,2,3}$, Silman Diawara ${ }^{4}$, Joel Mosnier ${ }^{1,2,3,5}$, Rémy Amalvict ${ }^{1,2,3,5}$, Nicolas Benoit ${ }^{1,2,3,5}$, Raymond Bercion ${ }^{6}$, Bécaye Fall ${ }^{4}$, Marylin Madamet ${ }^{1,2,3,5}$, Bruno Pradines ${ }^{1,2,3,4,5^{*}}$ and The French National Reference Centre for Imported Malaria Study Group

\begin{abstract}
Background: Resistance to all available anti-malarial drugs has emerged and spread including artemisinin derivatives and their partner drugs. Several genes involved in artemisinin and partner drugs resistance, such as pfcrt, pfmdr1, pfK13 or pfpm2, have been identified. However, these genes do not properly explain anti-malarial drug resistance, and more particularly clinical failures observed in Africa. Mutations in genes encoding for Plasmodium falciparum proteins, such as P. falciparum Acetyl-CoA transporter (PfACT), P. falciparum UDP-galactose transporter (PfUGT) and P. falciparum cyclic amine resistance locus (PfCARL) have recently been associated to resistance to imidazolopiperazines and other unrelated drugs.

Methods: Mutations on pfugt, pfact and pfcarl were characterized on 86 isolates collected in Dakar, Senegal and 173 samples collected from patients hospitalized in France after a travel in African countries from 2015 and 2016 to assess their potential association with ex vivo susceptibility to chloroquine, quinine, lumefantrine, monodesethylamodiaquine, mefloquine, dihydroartemisinin, artesunate, doxycycline, pyronaridine and piperaquine.

Results: No mutations were found on the genes pfugt and pfact. None of the pfcarl described mutations were identified in these samples from Africa. The K784N mutation was found in one sample and the K734M mutation was identified on $7.9 \%$ of all samples for pfcarl. The only significant differences in ex vivo susceptibility according to the K734M mutation were observed for pyronaridine for African isolates from imported malaria and for doxycycline for Senegalese parasites.
\end{abstract}

Conclusion: No evidence was found of involvement of these genes in reduced susceptibility to standard anti-malarial drugs in African P. falciparum isolates.

Keywords: Malaria, Plasmodium falciparum, Anti-malarial drug, In vitro, Resistance, Molecular marker, PfACT, PfUGT, PFCARL

\footnotetext{
*Correspondence: bruno.pradines@gmail.com

${ }^{1}$ Unité Parasitologie et Entomologie, Département de Microbiologie

et de maladies infectieuses, Institut de recherche biomédicale des

armées, IHU Méditerranée Infection, 19-21 Boulevard Jean Moulin,

13005 Marseille, France

Full list of author information is available at the end of the article
}

(c) The Author(s) 2019. This article is distributed under the terms of the Creative Commons Attribution 4.0 International License (http://creativecommons.org/licenses/by/4.0/), which permits unrestricted use, distribution, and reproduction in any medium, provided you give appropriate credit to the original author(s) and the source, provide a link to the Creative Commons license, and indicate if changes were made. The Creative Commons Public Domain Dedication waiver (http://creativecommons.org/ publicdomain/zero/1.0/) applies to the data made available in this article, unless otherwise stated. 


\section{Background}

According to the World Health Organization (WHO) recommendations, endemic countries have adopted the use of artemisinin-based combination therapy (ACT) to treat uncomplicated malaria cases [1]. Despite considerable progress, 219 million new malaria cases were reported with 435,000 deaths in 2017 [2]. Currently, artemisinin-based combinations are the most potent available anti-malarial drugs that are used for the reduction of the malaria global burden. Combination of a long acting drug with the short acting artemisinin is used to provide a protection against emergence of resistant parasites [3]. Mefloquine, lumefantrine, amodiaquine, and more recently piperaquine and pyronaridine are the available artemisinin-based partner drugs in ACT. Resistance to artemisinin described as a delayed parasite clearance after treatment has emerged in Southeast Asia $[4,5]$. It was also reported that low treatment success rate of ACT was associated with resistance to the partner drugs. This resistance has been described in Southeast Asia and may occur in Africa soon [6, 7].

In 2013, a molecular marker strongly associated with artemisinin resistance was identified as mutations in the Kelch 13 propeller domain (pfk13) in the Southeast Asia, but none of these mutations are yet documented in Africa [8, 9]. Pfk13 and/or the Ring-stage Survival Assay (RSA) are now used as tools to track artemisinin and artemisinin derivatives resistance in endemic areas in addition with epidemiological survey. However, recent studies proved that $p f k 13$ is not the only marker to be associated with artemisinin resistance [10]. Clinical failures with ACT have also been observed in African patients with $P$. falciparum parasites without $p f k 13$ polymorphism [11-15]. Polymorphisms in other genes, like $P$. falciparum actin-binding protein coronin, $P$. falciparum ubiquitin carboxyl-terminal hydrolase 1 (pfubp1) or $P$. falciparum clathrin vesicle-associated adaptor $2 \mu$ subunit (pfap2mu), have been also found to be associated with artemisinin resistance in African isolates [16, 17].

Additionally, resistance has also emerged to dihydroartemisinin-piperaquine, the most recently marketed ACT, in Cambodia and Vietnam [18-21]. In vitro and in vivo resistance to piperaquine has been associated with amplification of copy number of the plasmepsin II gene (pfpm2) in Cambodian isolates [22, 23]. However, amplification of this gene seems to be not associated with piperaquine in vitro and in vivo resistance particularly in Africa [24-29]. In conclusion, predictive molecular markers to track resistance to ACT in Africa are not yet identified.

Drug efficacy is modulated by parasite membrane proteins that are involved in drug transport. Two parasites membrane proteins, the Plasmodium falciparum chloroquine resistance transporter (PfCRT) and the $P$. falciparum multidrug resistance protein 1 (PfMDR1), both localized on the membrane of the digestive food vacuole, have been involved in drug resistance [30-32]. These proteins play an important role in trafficking of drugs between the parasite cytosol and the food vacuole. Their association with quinoline resistance has been demonstrated in many studies [30, 33-35].

But other less studied proteins may be involved in molecules traffic within the parasite. The $P$. falciparum Acetyl-CoA transporter (PfACT) and the P. falciparum UDP-galactose transporter (PfUGT) [36] are examples of major facilitator superfamily transporters and may share similar function [37]. The protein PfACT function is not known yet, but its parasite localization and its homologues form in other organisms suggest that this protein may be involved in intracellular translocation of small molecules including metabolites, nucleosides, oligosaccharides, amino-acids, oxyanions and drugs. These two putative transporters have been associated with in vitro resistance to imidazolopiperazines, and more particularly to KAF156 and GNF179, two new potential antimalarial compounds that are under clinical evaluation [38]. KAF156 showed high in vitro activity and in vivo efficacy against $P$. falciparum and $P$. vivax and in vitro and in vivo transmission blocking activity $[39,40]$. KAF156 did not show in vitro crossresistance with artemisinin and lumefantrine [38]. GNF179 was active in vitro against blood stages as well as liver stages [41]. Resistant parasites to KAF156 and GNF179 generated in vitro showed different mutations (A94T, R108K, S110R, D165N, C183*, S242*, L253* and G559K) in the pfact gene and a substitution of a phenylalanine by a valine at the position 37 of the gene pfugt (F37V) [35]. Additionally, the generation of resistant parasites to KAF156 and GNF179 lead to mutations (L830V, S1076N/I, V1103L, I1139K) in the P. falciparum cyclic amine resistance locus (PfCARL) [38, 39, 41-43]. Pfcarl plays a role in protein folding within the endoplasmic reticulum [44]. Mutations in pfcarl did not lead to in vitro resistance to artemisinin, chloroquine and mefloquine in two mutant strains [42]. These three genes seem to be multidrugresistance genes specific to resistance to benzimidazolyl piperidines and imidazolopiperazines [38, 42, 43]. However, the data on cross-resistance with standard anti-malarial drugs were obtained from in vitro selection of $P$. falciparum mutant clones. Neither the involvement of these three genes in resistance to imidazolopiperazines nor cross-resistance with standard anti-malarial drugs have been assessed in field isolates. There are no data on polymorphisms and their prevalence in natural parasite populations, or in the 
involvement of these three genes on the susceptibility of ACT partner drugs such as piperaquine, pyronaridine, lumefantrine or amodiaquine against field $P$. falciparum isolates.

The present study aimed to evaluate the prevalence of polymorphisms in pfact, pfugt and pfcarl genes and to evaluate their association with reduced susceptibility to common anti-malarial drugs on 259 P. falciparum African isolates.

\section{Methods}

\section{Sample collection}

Eighty-six of the samples used were collected from falciparum malaria patients, who were recruited at the Hôpital Principal de Dakar, Senegal after the rainy seasons between 2013 and 2015 in the context of studies on evaluation of anti-malarial drug resistance [15, 45-47]. A total of 173 samples collected between 2015 and 2016 from patients hospitalized in France with imported malaria from a malaria-endemic country, especially from Cameroon, Côte d'Ivoire, Central African Republic, Burkina Faso, Togo, Gabon, Guinea and Senegal (Fig. 1) were additionally used to complete the study. Twelve samples have an unknown African origin. The samples were sent from different civilian or military hospitals of the French National Reference Centre for Imported Malaria network (Aix en Provence, Bordeaux, Fréjus, Marseille, Montpellier, Nice, Toulon and Toulouse) to the French National Reference Centre for Malaria (IRBA, IHU Méditerranée Infection Marseille).

Peripheral venous blood samples were collected in Vacutainer $^{\circledR}$ ACD tubes (Becton-Dickinson, Rutherford, NJ, USA) prior to patient treatment for parasite detection. The diagnosis was performed on thin blood smears that were stained using a RAL ${ }^{\circledR}$ kit (Réactifs RAL, Paris, France), based on eosin and methylene blue, to determine the $P$. falciparum density. The diagnosis of $P$. falciparum mono-infection was confirmed by real time PCR (LightCycler 2.0, Roche Group, Switzerland), as previously described [48]. An aliquot of each sample was collected and stored at $-20^{\circ} \mathrm{C}$ for molecular study. Parasitized erythrocytes were washed three times in RPMI 1640 medium (Invitrogen, Paisley, UK) buffered with $25 \mathrm{mM}$ HEPES and $25 \mathrm{mM} \mathrm{NaHCO}$. If parasitaemia exceeded $0.1 \%$, infected erythrocytes were diluted to $0.1 \%$ with uninfected erythrocytes (human blood type $\mathrm{A}+$ ) and resuspended in RPMI 1640 medium supplemented with $10 \%$ human serum (Abcys S.A. Paris, France), for a final haematocrit of $1.5 \%$. The susceptibility of the isolates to the different anti-malarial drugs was assessed without culture adaptation.

\section{Drugs and ex vivo assay}

Chloroquine $(\mathrm{CQ})$, quinine $(\mathrm{QN})$, dihydroartemisinin (DHA) and doxycycline (DOX) were obtained from Sigma (Saint Louis, MO, USA), monodesethylamodiaquine (DQ) from the World Health Organization (Geneva, Switzerland), mefloquine (MQ) from Roche (Paris, France), lumefantrine (LMF) from Novartis Pharma (Basel, Switzerland), and artesunate (AS), piperaquine (PPQ) and pyronaridine (PND) from Shin Poong Pharm Co. (Seoul, Korea).

For each experiment, parasitized erythrocytes (final parasitemia at $0.5 \%$ and a final haematocrit at $1.5 \%$ ) were aliquoted into 96-well plates that were pre-dosed with a concentration gradient of anti-malarial drugs. The plates were incubated for $72 \mathrm{~h}$ at $37{ }^{\circ} \mathrm{C}$ in controlled atmosphere at $85 \% \mathrm{~N}_{2}, 10 \% \mathrm{O}_{2}, 5 \% \mathrm{CO}_{2}$ for imported isolates and in a sealed bag with atmospheric generators for capnophilic bacteria using Genbag $\mathrm{CO} 2{ }^{\circledR}$ at $5 \% \mathrm{CO}_{2}$ and $15 \%$ $\mathrm{O}_{2}$ (BioMérieux, Marcy l'Etoile, France) for Senegalese isolates [49]. The drug susceptibility assay was performed using the HRP2 ELISA-based assay Malaria Ag Celisa kit (ref KM2159, Cellabs PTY LDT, Brookvale, Australia), as previously described [46].

Each batch of plates was validated using the CQ-resistant W2 strain (isolated in Indochina; obtained from MR4, VA, USA) in four independent experiments using the same conditions described below.

The mean $50 \%$ inhibitory concentration $\left(\mathrm{IC}_{50}\right)$ values for the chloroquine-resistant W2 strain for the different batches used over 2 years in controlled atmosphere at $85 \% \mathrm{~N}_{2}, 10 \% \mathrm{O}_{2}, 5 \% \mathrm{CO}_{2}$ were $484 \pm 40 \mathrm{nM}$ for $\mathrm{CQ}$, $388 \pm 29 \mathrm{nM}$ for $\mathrm{QN}, 97 \pm 18 \mathrm{nM}$ for $\mathrm{DQ}, 1.0 \pm 0.4 \mathrm{nM}$ for LMF, $26.3 \pm 3.1 \mathrm{nM}$ for MQ, $54.1 \pm 5.4 \mathrm{nM}$ for PPQ, $20.4 \pm 3.4 \mathrm{nM}$ for PND, $2.5 \pm 0.4 \mathrm{nM}$ for DHA, $1.5 \pm 0.3 \mathrm{nM}$ for AS and $11.5 \pm 1.9 \mu \mathrm{M}$ for DOX. A comparison of the W2 susceptibility data of the ten anti-malarial drugs between the different batches of plates indicated that there was no significant difference in the responses to anti-malarial drugs over the 2 years $(0.583<\mathrm{p}<0.993)$. The cut-off values for the reduced ex vivo susceptibility or resistance were as follows: $100 \mathrm{nM}(\mathrm{CQ}), 800 \mathrm{nM}(\mathrm{QN}), 80 \mathrm{nM}$ (DQ), $30 \mathrm{nM}$ (MQ), $150 \mathrm{nM}$ (LMF), $135 \mathrm{nM}$ (PPQ), $60 \mathrm{nM}$ (PND), $10.5 \mathrm{nM}$ (DHA and AS) and $35 \mu \mathrm{M}$ (DOX) [50, 51].

The mean $\mathrm{IC}_{50}$ values for the W2 strain for the different batches used during the 3 years using atmospheric generators for capnophilic bacteria were $292 \mathrm{nM}$ for $\mathrm{CQ}, 275 \mathrm{nM}$ for QN, $72 \mathrm{nM}$ for $\mathrm{DQ}, 13.7 \mathrm{nM}$ for LMF, 15.4 $\mathrm{nM}$ for $\mathrm{MQ}, 32.5 \mathrm{nM}$ for $\mathrm{PPQ}, 26.4 \mathrm{nM}$ for PND, $1.27 \mathrm{nM}$ for DHA, and $10.7 \mu \mathrm{M}$ for DOX. A comparison of W2 susceptibility data for the nine anti-malarial drugs indicated that there was no significant difference in the responses to anti-malarial drugs over the 3 years $(0.39<\mathrm{p}<0.95)$. The cut-off values for the reduced ex vivo susceptibility or resistance were as follows: 


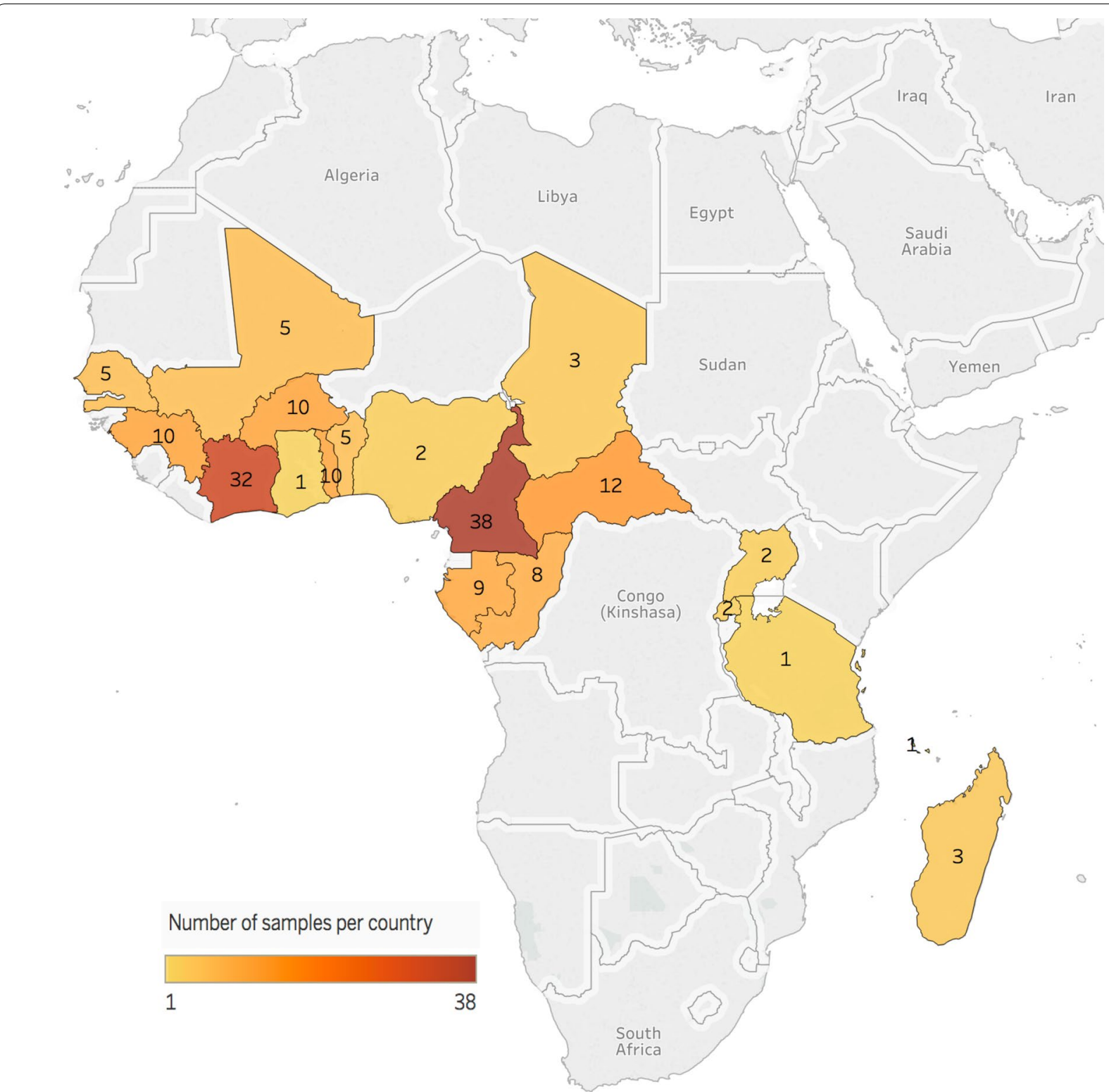

Fig. 1 Geographical repartition and isolate number per country of the Plasmodium falciparum isolates collected between 2015 and 2016 from patients hospitalized in France with imported malaria from Africa

$77 \mathrm{nM}(\mathrm{CQ}), 611 \mathrm{nM}(\mathrm{QN}), 61 \mathrm{nM}(\mathrm{DQ}), 30 \mathrm{nM}(\mathrm{MQ})$, $115 \mathrm{nM}$ (LMF), $135 \mathrm{nM}$ (PPQ), $60 \mathrm{nM}$ (PND), $12 \mathrm{nM}$ (DHA and AS) and $37 \mu \mathrm{M}(\mathrm{DOX})[46,47,52]$.

The polymorphic genetic markers $m s p 1$ and $m s p 2$ and microsatellite markers specific to P. falciparum were genotyped at least once a month to verify W2 clonality $[53,54]$.

\section{Nucleic acid extraction}

Total genomic DNA of each sample was isolated and purified using the QIAamp ${ }^{\circledR}$ DNA Mini kit according to the manufacturer's recommendations (Qiagen, Hilden, Germany).

\section{Genotyping of pfact, pfugt and pfcarl}

The three genes, pfact (PF3D7_1036800), pfugt (PF3D7_1113300) and pfcarl (PF3D7_0321900), were amplified by polymerase chain reaction using the oligonucleotide primer pairs described in Table 1.

Two primer pairs were used to amplify the $p f a c t$ fragments (1042 and 407 nucleotides). The reaction mixture contained $200 \mathrm{ng}$ of genomic DNA, $0.32 \mu \mathrm{M}$ of each primer, $1 \times$ final of reaction buffer $(750 \mathrm{mM}$ of Tris- $\mathrm{HCl}$, $200 \mathrm{mM}$ of $\left(\mathrm{NH}_{4}\right)_{2} \mathrm{SO}_{4}, 0.1 \%(\mathrm{v} / \mathrm{v})$ Tween 20 and stabilizer, $\mathrm{pH}$ 8.8), $2.5 \mathrm{mM}$ of $\mathrm{MgCl}_{2}, 200 \mu \mathrm{M}$ of dNTP mixture and $1 \mathrm{U}$ of Hot Diamond Taq ${ }^{\circledR}$ polymerase (Eurogentec, 
Table 1 Forward and reverse primers, hybridization temperature (Tm) and $\mathrm{MgCl}_{2}$ concentration used for $P C R$

\begin{tabular}{|c|c|c|}
\hline Gene & Forward and reverse primers & $\mathrm{Tm}$ \\
\hline pfugt (PF3D7_1113300) & $\begin{array}{l}\text { Pfugt-F } \\
\text { 5'-GCT CAG GTA TGT TTT GGA AG-3' } \\
\text { Pfugt-R } \\
\text { 5'-GTC CAG TAA GTC CGT CAC AT-3' }\end{array}$ & $52^{\circ} \mathrm{C}$ \\
\hline \multirow[t]{3}{*}{ pfact (PF3D7_1036800) } & $\begin{array}{l}\text { Pfact-1F } \\
5^{\prime}-\text { TTG TGT AAC CCC CAC TAA AC-3' }\end{array}$ & $54^{\circ} \mathrm{C}$ \\
\hline & $\begin{array}{l}\text { Pfact-1R } \\
\text { 5'-TTA TCG TCA CAC TTT TGT GC-3' } \\
\text { Pfact_seq 1F } \\
\text { 5'-CTA TTT TGC AGT TTT ACG ATG-3' }\end{array}$ & $54^{\circ} \mathrm{C}$ \\
\hline & $\begin{array}{l}\text { Pfact-2F } \\
\text { 5'-TGA TTA CAC TGA TAA GGA ATT } \\
\text { TTG-3' } \\
\text { Pfact-2R } \\
\text { 5'-TTC GTT CTC CAA TCTTCT AAA-3' }\end{array}$ & $48^{\circ} \mathrm{C}$ \\
\hline pfcarl (PF3D7_0321900) & $\begin{array}{l}\text { Pfcarl-F } \\
\text { 5'-TTG CCA TGA TTT GAA GTA CA-3' } \\
\text { Pfcarl-R } \\
\text { 5'-AAC CATTTT CGT ATT CAT GTT-3' }\end{array}$ & $50^{\circ} \mathrm{C}$ \\
\hline
\end{tabular}

Liège, Belgium) in a final volume of $25 \mu \mathrm{L}$. The thermal cycler (Life Eco V 2.04; Bioer, China) was programmed as follows: $95{ }^{\circ} \mathrm{C}$ for $10 \mathrm{~min}, 40$ cycles of $95^{\circ} \mathrm{C}$ for $30 \mathrm{~s}$, hybridization temperature for $45 \mathrm{~s}$ (Table 1 ), $72{ }^{\circ} \mathrm{C}$ for $1 \mathrm{~min} 20 \mathrm{~s}$, and a final 10 -min extension step at $72^{\circ} \mathrm{C}$.

A fragment of 600 nucleotides of pfugt gene was amplified using the two primer pairs described in Table 1. The reaction mixture contained $200 \mathrm{ng}$ of genomic DNA, $0.32 \mu \mathrm{M}$ of each primer, $1 \times$ final of reaction buffer (750 mM of Tris- $\mathrm{HCl}, 200 \mathrm{mM}$ of $\left(\mathrm{NH}_{4}\right)_{2} \mathrm{SO}_{4}, 0.1 \%$ (v/v) Tween 20 and stabilizer, $\mathrm{pH} 8.8$ ), $2.5 \mathrm{mM}$ of $\mathrm{MgCl}_{2}$, $200 \mu \mathrm{M}$ of dNTP mixture and $1 \mathrm{U}$ of Hot Diamond Taq ${ }^{\mathrm{B}}$ polymerase (Eurogentec, Liège, Belgium) in a final volume of $25 \mu \mathrm{L}$. The thermal cycler (Life Eco V 2.04; Bioer, China) was programmed as follows: $95^{\circ} \mathrm{C}$ for $10 \mathrm{~min}, 40$ cycles of $95{ }^{\circ} \mathrm{C}$ for $30 \mathrm{~s}$, hybridization temperature for $45 \mathrm{~s}$ (Table 1 ), $72{ }^{\circ} \mathrm{C}$ for $45 \mathrm{~s}$, and a final 10 -min extension step at $72{ }^{\circ} \mathrm{C}$.

To analyse pfcarl mutations, a fragment of 821 nucleotides was amplified using the specific primer pair described in Table 1 . The reaction mixture contained $200 \mathrm{ng}$ of genomic DNA, $0.32 \mu \mathrm{M}$ of each primer, $1 \times$ final of reaction buffer $(750 \mathrm{mM}$ of Tris- $\mathrm{HCl}, 200 \mathrm{mM}$ of $\left(\mathrm{NH}_{4}\right)_{2} \mathrm{SO}_{4}, 0.1 \%(\mathrm{v} / \mathrm{v})$ Tween 20 and stabilizer, $\left.\mathrm{pH} 8.8\right)$, $2.5 \mathrm{mM}$ of $\mathrm{MgCl}_{2}, 200 \mu \mathrm{M}$ of dNTP mixture and $1 \mathrm{U}$ of Hot Diamond Taq ${ }^{\circledR}$ polymerase (Eurogentec, Liège, Belgium) in a final volume of $25 \mu \mathrm{L}$. The thermal cycler (Life Eco V 2.04; Bioer, China) was programmed as follows: $95^{\circ} \mathrm{C}$ for $10 \mathrm{~min}, 40$ cycles of $95^{\circ} \mathrm{C}$ for $30 \mathrm{~s}$, hybridization temperature for $45 \mathrm{~s}$ (Table 1 ), $72{ }^{\circ} \mathrm{C}$ for $1 \mathrm{~min}$, and a final 10-min extension step at $72^{\circ} \mathrm{C}$.
The purified amplicons were sequenced using corresponding PCR primers and a sequencing primer for $p f a c t$ first fragment (Table 1) on an ABI Prism 3100 analyser (Applied Biosystems, Villebon sur Yvette, France) according to the manufacturers' instructions. Sequences were aligned and compared with the corresponding sequences of the P. falciparum 3D7 using Vector NTI 10.3.0 (Invitrogen, Cergy Pontoise, France) to identify potential SNPs.

\section{Data and statistical analysis}

Samples and genotype distribution were performed on Tableau Desktop (Version 10.3.2). Plots of $\mathrm{IC}_{50}$ distribution were performed using $\mathrm{R}$ software. Statistical analyses were performed on SPSS, Version 16 (IBM, USA). Normally distributed $\mathrm{IC}_{50} \mathrm{~s}$ data for each drug were assessed by the Kolmogorov-Smirnov test.

\section{Results}

\section{Ex vivo susceptibility to anti-malarial drugs}

The average parameters of the $\mathrm{IC}_{50}$ values for the ten antimalarial drugs are presented in Table 2. The distribution of the $\mathrm{IC}_{50}$ values are showed in Fig. 2 for the Senegalese isolates and in Fig. 3 for malaria imported isolates.

\section{Gene sequence polymorphism analysis}

The previously identified mutations at position 94, 108, $110,165,183,242,253$ and 559 in the pfact gene were not detected and no other polymorphism was identified in the 259 African isolates. For the gene pfugt, all samples were also wild type at position 37 and no other polymorphism was identified within the sequences.

None of the mutations of the pfcarl gene involved in imidazolopiperazine resistance was found in African $P$. falciparum isolates. Three new mutations were detected: the $\mathrm{K} 784 \mathrm{~N}$ mutation present in one isolate, the $\mathrm{K} 734 \mathrm{M}$ mutation $(8.9 \%$ on Senegalese samples and $7.5 \%$ on malaria imported samples) and the K903E mutation which was found on both all Senegalese and malaria imported valid sequences (100\%). The only significant differences in ex vivo susceptibility according to the K734M mutation were observed for PND for African isolates from imported malaria $(p=0.028 ; 22.1 \mathrm{nM}$ vs. $39.2 \mathrm{nM}$ ) and for DOX for Senegalese parasites $(\mathrm{p}=0.034 ; 26.4 \mu \mathrm{M}$ vs. $8.0 \mu \mathrm{M})$ (Table 3). The difference in PND $\mathrm{IC}_{50} \mathrm{~s}$ according to the wild type/mutant haplotype of PfCARL was not significant by pooling all the $\mathrm{IC}_{50} \mathrm{~s}$ from imported and Senegalese isolates $(20.4 \mathrm{nM}$ vs. $30.4 \mathrm{nM} ; \mathrm{p}=0.202$ ). There was no significant difference between the prevalences of $734 \mathrm{M}$ mutated parasites in susceptible isolates and that in parasites with reduced susceptibility to the different anti-malarial drugs tested in the present study ( $\mathrm{p}$ values between 0.053 and 1 [Fisher's exact test]) (Table 4). 
Table 2 Average parameters of $P$. falciparum susceptibility to chloroquine (CQ), quinine (QN), monodesethylamodiaquine (DQ), mefloquine (MQ), lumefantrine (LMF), pyronaridine (PND), piperaquine (PPQ), dihydroartemisinin (DHA), artesunate (AS) and doxycycline (DOX)

\begin{tabular}{|c|c|c|c|c|c|c|c|c|}
\hline \multirow[t]{3}{*}{ Drugs } & \multicolumn{4}{|c|}{ Isolates from Senegal $(n=86)$} & \multicolumn{4}{|c|}{$\begin{array}{l}\text { African isolates from imported malaria analyzed for pfcarl } \\
(n=173)\end{array}$} \\
\hline & \multicolumn{2}{|l|}{$I C_{50}$} & \multirow{2}{*}{$\begin{array}{l}\text { Geometric } \\
\text { mean }\end{array}$} & \multirow[t]{2}{*}{ Resistance \% } & \multicolumn{2}{|l|}{$\mathrm{IC}_{50}$} & \multirow[t]{2}{*}{ Geometric mean } & \multirow[t]{2}{*}{ Resistance \% } \\
\hline & Min & Max & & & Min & Max & & \\
\hline CQ & 0.6 & 954.9 & 60.0 & 48.6 & 6.27 & 791.6 & 69.7 & 28.3 \\
\hline QN & 5 & 1429.8 & 113 & 5.7 & 5.29 & 690.1 & 127.8 & 0 \\
\hline DQ & 1.6 & 227.3 & 21.7 & 23.6 & 1.9 & 196.43 & 29.2 & 8.1 \\
\hline MQ & 2 & 109.2 & 24.8 & 48.5 & 4.4 & 173.43 & 39.5 & 67.7 \\
\hline LMF & 0.5 & 82.9 & 4.53 & 0 & 0.33 & 16.66 & 1.4 & 0 \\
\hline PND & 0.4 & 116.6 & 16.4 & 3.1 & 0.8 & 122.96 & 16.5 & 6.1 \\
\hline PPQ & 3.2 & 241.9 & 37.4 & 6.1 & 0.94 & 137.51 & 34.3 & 0.6 \\
\hline DHA & 0.08 & 17.28 & 1.36 & 1.5 & 0.09 & 28.11 & 4.1 & 17.5 \\
\hline AS & 0.06 & 18.06 & 2.18 & 3.5 & 0.1 & 23.56 & 3.7 & 9.8 \\
\hline DOX & 0.9 & 121.6 & 23.0 & 28.2 & 0.46 & 41.14 & 16.2 & 17.3 \\
\hline
\end{tabular}

$\mathrm{IC}_{50}$ in $\mathrm{nM}$ for $\mathrm{CQ}, \mathrm{QN}, \mathrm{DQ}, \mathrm{MQ}, \mathrm{LMF}, \mathrm{PND}, \mathrm{PPQ}, \mathrm{DHA}, \mathrm{AS}$

$\mathrm{IC}_{50}$ in $\mu \mathrm{M}$ for DOX

\section{Discussion}

The aim of the present study was to determine whether described SNPs in the genes pfact, pfugt and pfcarl, involved in imidazolopiperazine resistance, are found in African isolates, their prevalence and if these mutations are associated with common anti-malarial drug susceptibility. The main limitation of this study is the low number of parasites with reduced susceptibility to LMF ( $0 \%$ for Senegalese isolates and imported isolates), QN (5.7\% for Senegalese isolates and 0\% for imported isolates), PND (3.1\% for Senegalese isolates and 6.1\% for imported isolates) and PPQ (6.1\% for Senegalese isolates and 0.6\% for imported isolates). However, $\mathrm{IC}_{50}$ values were distributed in a broad way (Figs. 2, 3). There was no polymorphism in the analysed sequence of pfact and pfugt. None of the mutations of the pfcarl gene involved in imidazolopiperazine resistance was found in African $P$. falciparum isolates but three other ones were identified: the $\mathrm{K} 784 \mathrm{~N}$ mutation present in one isolate, the K734M mutation $(7.9 \%)$ (prevalence of $8.9 \%$ in Senegalese samples and $7.5 \%$ in malaria imported samples from Africa) and the K903E mutation (100\%). These mutations were also found in P. falciparum sequences filed on PlasmoDB in similar proportions: $0.4 \%$ for K784N, $11 \%$ for K734M and $99 \%$ for K903E mutation. The K734M seemed to be not associated with susceptibility to standard anti-malarial drugs. No evidence was found of prevalence difference between susceptible isolates and parasites with reduced susceptibility. Only parasites collected from African imported malaria carrying the $\mathrm{K} 734 \mathrm{M}$ mutation were significantly less susceptible to pyronaridine than wild
P. falciparum parasites ( $39.2 \mathrm{nM}$ vs. $22.1 \mathrm{nM} ; \mathrm{p}=0.028)$. However, these data should be taken with caution due to the low number of samples, and more specially parasites with reduced susceptibility to anti-malarial drugs. It is necessary to further assess more $P$. falciparum isolates to ascertain the potential association between the pfcarl K734M mutation and reduced susceptibility to pyronaridine.

A limitation of this kind of study is the strength of the correlation between ex vivo or in vitro studies and therapeutic efficacy assays. Clinical failures with dihydroartemisinin/piperaquine in Cambodia were associated with resistant phenotype but this association has not been shown yet in Africa [22, 23, 55]. Association between these two methods is not fully established for some anti-malarial drugs like mefloquine, lumefantrine, piperaquine, pyronaridine, and more particularly in Africa. The main explanations for a lack of correlation are that in vitro assays and clinical studies of therapeutic efficacy do not address the same biological and clinical endpoints and the cut off for in vitro reduced susceptibility are usually fixed arbitrarily without any reference to predictable clinical and parasitological response [56]. Many factors, and more specially host factors like acquired immunity, nutritional status, pharmacokinetic characteristics, interact in drug in vivo efficacy. However, the major criteria for a valid in vitro or ex vivo threshold should be the association with clinical outcome.

Additionally, in the absence of standardized ex vivo and in vitro tests, it is very difficult to compare data 


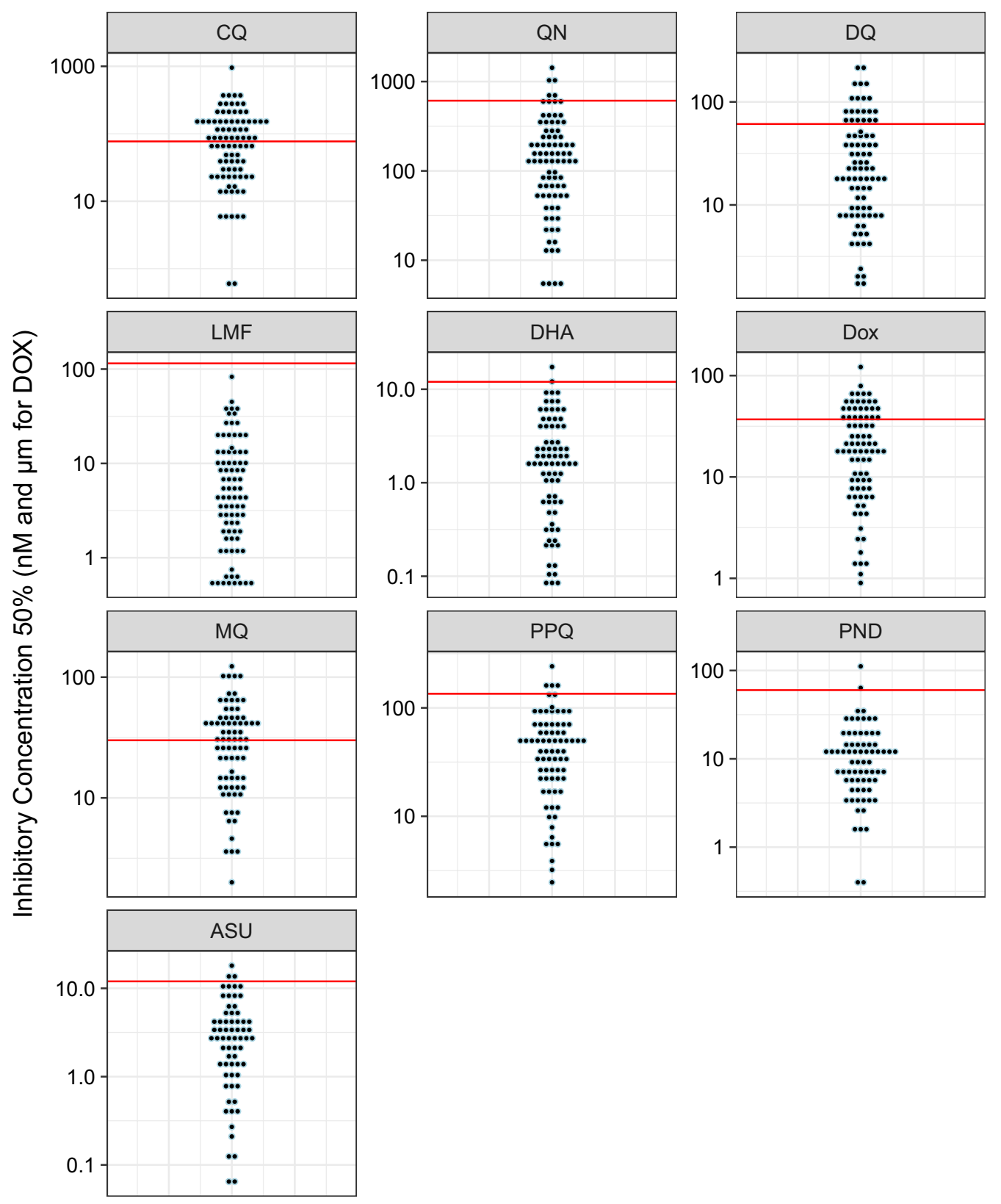

Fig. 2 Dot plot of the $I C_{50}$ total distribution of each Senegalese Plasmodium falciparum isolate assessed ex vivo for chloroquine (CQ), quinine $(\mathrm{QN})$, monodesethylamodiaquine $(\mathrm{DQ})$, mefloquine $(\mathrm{MQ})$, lumefantrine $(\mathrm{LMF})$, piperaquine $(\mathrm{PPQ})$, pyronaridine $(\mathrm{PND})$, dihydroartemisinin $(\mathrm{DHA})$, artesunate (AS) and doxycycline (DOX). The red line represents the in vitro threshold of reduced susceptibility

from different laboratories. $\mathrm{IC}_{50}$ and cut-off values for in vitro resistance are specific to the methodology. The in vitro effects and the $\mathrm{IC}_{50}$ values for anti-malarial drugs depend on incubation conditions [57, 58], gas conditions (e.g., the effects of $\mathrm{O}_{2}$ and $\mathrm{CO}_{2}$ ) $[45,59]$, and methodology (e.g., use of an isotopic test vs. an immune-enzymatic test) [60]. These differences in methodology must be taken into account when comparing and analysing resistance data from different studies. The use of a reference strain as internal control is essential to validate and compare data obtained with several batches of plates. 

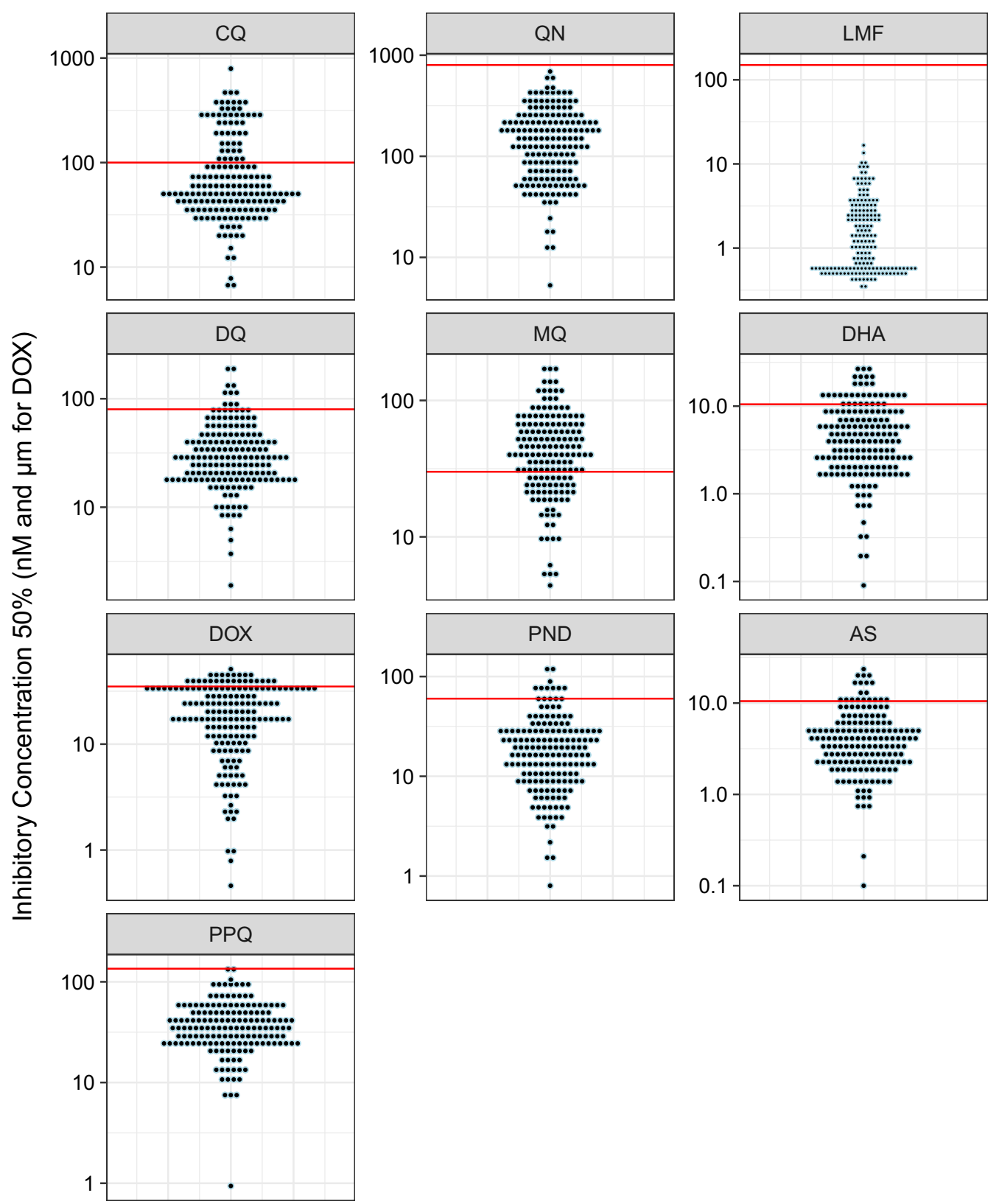

Fig. 3 Dot plot of the $I_{50}$ total distribution of each Plasmodium falciparum isolate from imported malaria to France assessed ex vivo for chloroquine (CQ), quinine (QN), monodesethylamodiaquine $(D Q)$, mefloquine $(M Q)$, lumefantrine $(L M F)$, piperaquine (PPQ), pyronaridine (PND), dihydroartemisinin (DHA), artesunate (AS) and doxycycline (DOX). The red line represents the in vitro threshold of reduced susceptibility

\section{Conclusion}

None of the mutations of the pfact, pfugt and pfcarl genes involved in imidazolopiperazine or benzimidazolyl piperidine resistance was found in 259 African P. falciparum isolates. The prevalence of these mutations in Africa was very low. This absence of mutations involved in imidazolopiperazine or benzimidazolyl piperidine resistance suggests that the pfact, pfugt and pfcarl genes are not involved in quinoline ex vivo resistance ( 28.3 to $48.6 \%$ of resistance to chloroquine, 8.1 to $23.6 \%$ of resistance to desethylamodiaquine or 48.5 to $67.7 \%$ of resistance to mefloquine) and in doxycycline reduced susceptibility (17.3 to $28.2 \%$ ) in the 259 P. falciparum African isolates which were evaluated in the present study. Additionally, the $734 \mathrm{M}$ mutation identified in the pfcarl gene at a rate of $7.9 \%$ was not associated with ex vivo susceptibility to standard anti-malarial drugs. This absence of identification 
Table 3 Ex vivo susceptibility of African Plasmodium falciparum isolates to chloroquine (CQ), quinine (QN), monodesethylamodiaquine (DQ), mefloquine (MQ), lumefantrine (LMF), piperaquine (PPQ), pyronaridine (PND), dihydroartemisinin (DHA), artesunate (AS) and doxycycline (DOX) according to the K734M mutation in the pfcarl gene

\begin{tabular}{|c|c|c|c|c|c|c|c|c|c|c|}
\hline \multirow[t]{3}{*}{ Drug } & \multicolumn{5}{|c|}{ Isolates from Senegal } & \multicolumn{5}{|c|}{ African isolates from imported malaria } \\
\hline & \multicolumn{2}{|c|}{ Wild-type K734 $(n=61)$} & \multicolumn{2}{|c|}{ Mutated 734M $(n=6)$} & \multirow[t]{2}{*}{ p-value } & \multicolumn{2}{|c|}{ Wild-type K734 ( $n=160)$} & \multicolumn{2}{|c|}{ Mutated 734 M $(n=13)$} & \multirow[t]{2}{*}{ p-value } \\
\hline & Mean IC 50 & Min and Max & Mean $\mathrm{IC}_{50}$ & Min and Max & & Mean IC 50 & Min and Max & Mean $\mathrm{IC}_{50}$ & Min and Max & \\
\hline CQ & 110.7 & $0.6 / 954.9$ & 87.7 & $17.0 / 163$ & 0.835 & 109.1 & 7.2/791.6 & 107.6 & $6.27 / 383.8$ & 0.616 \\
\hline QN & 225.8 & $5 / 1429.8$ & 69.0 & $15.0 / 140.1$ & 0.087 & 176.0 & $11.53 / 690.1$ & 137.8 & $5.29 / 338.3$ & 0.227 \\
\hline $\mathrm{DQ}$ & 36.9 & $1.6 / 202.6$ & 41.8 & $2.4 / 140.0$ & 0.690 & 37.1 & $3.72 / 196.4$ & 39.1 & $1.9 / 105.6$ & 0.588 \\
\hline MQ & 37.6 & 2.0/123.0 & 19.6 & $10.0 / 44.0$ & 0.088 & 48.8 & $4.4 / 173.4$ & 60.0 & $21.16 / 172.6$ & 0.398 \\
\hline LMF & 9.9 & $0.5 / 82.9$ & 5.9 & $1.2 / 12.6$ & 0.970 & 2.2 & $0.33 / 13.5$ & 2.6 & $0.37 / 16.7$ & 0.704 \\
\hline PPQ & 56.1 & $3.2 / 241.9$ & 37.9 & $12.0 / 100.0$ & 0.350 & 39.9 & $0.94 / 137.5$ & 47.4 & $14.3 / 96.8$ & 0.293 \\
\hline PND & 15.4 & $0.4 / 111.6$ & 9.5 & $4.8 / 15.2$ & 0.700 & 22.1 & $0.8 / 114.6$ & 39.2 & $7.09 / 122.9$ & 0.028 \\
\hline DHA & 2.9 & $0.8 / 17.3$ & 2.1 & $0.09 / 9.2$ & 0.101 & 6.0 & $0.19 / 28.1$ & 7.1 & $0.09 / 23.3$ & 0.404 \\
\hline AS & 4.2 & $0.06 / 18.1$ & 4.6 & $2.5 / 8.5$ & 0.709 & 5.0 & $0.1 / 23.6$ & 5.8 & $1.9 / 17.9$ & 0.362 \\
\hline DOX & 26.4 & 0.9/79.0 & 8.0 & $1.5 / 18.4$ & 0.034 & 22.0 & $0.79 / 51.1$ & 16.3 & $0.46 / 39.4$ & 0.144 \\
\hline
\end{tabular}

Table 4 Prevalences of Plasmodium falciparum isolates with the 734M mutation in the P. falciparum cyclic amine resistance locus (pfcarl) according to parasite susceptibility to chloroquine (CQ), quinine (QN), lumefantrine (LMF), desethylamodiaquine (DQ), mefloquine (MQ), pyronaridine, (PND), piperaquine (PPQ), dihydroartemisinin (DHA), artesunate (AS) and doxycycline (DOX)

\begin{tabular}{|c|c|c|c|c|}
\hline \multirow[t]{2}{*}{ Drug } & \multirow[t]{2}{*}{ Reduced-susceptible cutoff } & \multicolumn{2}{|c|}{$\begin{array}{l}\% \text { of isolates with the } 734 \mathrm{M} \text { mutation (no. of isolates with the } 734 \mathrm{M} \\
\text { mutation/total no. of susceptible or resistant isolates }\end{array}$} & \multirow{2}{*}{$\begin{array}{l}\text { p value } \\
\text { (Fisher's } \\
\text { exact test }\end{array}$} \\
\hline & & Susceptible parasites & $\begin{array}{l}\text { Parasites with reduced } \\
\text { susceptibility }\end{array}$ & \\
\hline $\mathrm{CQ}$ & $77^{\mathrm{a}}$ or $100^{\mathrm{b}} \mathrm{nM}$ & $7.7(12 / 155)$ & $8.2(7 / 85)$ & 1 \\
\hline QN & $611^{\mathrm{a}}$ or $800^{\mathrm{b}} \mathrm{nM}$ & $8.0(19 / 235)$ & $0(0 / 5)$ & 1 \\
\hline LMF & $150 \mathrm{nM}$ & $8.0(19 / 235)$ & $0(0 / 0)$ & 1 \\
\hline $\mathrm{DQ}$ & $61^{\mathrm{a}}$ or $80^{\mathrm{b}} \mathrm{nM}$ & $7.2(15 / 209)$ & $12.9(4 / 31)$ & 0.28 \\
\hline MQ & $30 \mathrm{nM}$ & $7.4(7 / 95)$ & $6.9(10 / 145)$ & 1 \\
\hline PND & $60 \mathrm{nM}$ & $6.9(16 / 233)$ & $28.6(2 / 7)$ & 0.089 \\
\hline PPQ & $135 \mathrm{nM}$ & $7.2(17 / 236)$ & $0(0 / 4)$ & 1 \\
\hline DHA & $12^{\mathrm{a}}$ or $10.5^{\mathrm{b}} \mathrm{nM}$ & $7.4(16 / 217)$ & $13.0(3 / 23)$ & 0.41 \\
\hline AS & 12 or $10.5 \mathrm{nM}$ & $6.7(15 / 225)$ & $25.0(3 / 12)$ & 0.053 \\
\hline DOX & $37^{\mathrm{a}}$ or $35^{\mathrm{b}} \mathrm{nM}$ & $8.2(16 / 194)$ & $6.5(3 / 46)$ & 1 \\
\hline
\end{tabular}

a Cutoff estimated for ex vivo test in seal bag with atmospheric generator using Genbag $\mathrm{CO}^{\circledR}[52]$

b Cutoff estimated for ex vivo test in controlled atmosphere for imported isolates [50, 51]

of the mutations in pfact, pfugt and pfcarl genes, which are involved in imidazolopiperazine resistance, in 259 African $P$. falciparum isolates, is suggesting a very low prevalence of resistant parasites, encouraging data for the use of KAF156 and GNF179 for malaria treatment.

\section{Abbreviations}

ACT: artemisinin-based combination therapy; AS: artesunate; CQ: chloroquine; DHA: dihydroartemisinin; DNA: deoxyribonucleic acid; DQ: monodesethylamodiaquine; DOX: doxycycline; $I C_{50}$ : 50\% inhibitory concentration; LMF: lumefantrine; MQ: mefloquine; PfACT: Plasmodium falciparum Acetyl-CoA transporter; pfap2mu: P. falciparum clathrin vesicle-associated adaptor $2 \mu$ subunit; PfCARL: Plasmodium falciparum cyclic amine resistance locus; PfCRT: Plasmodium falciparum chloroquine resistance transporter; PfK13: Plasmodium falciparum Kelch 13; PfMDR1: Plasmodium falciparum multidrug resistance 1 gene; pfubp 1: P. falciparum ubiquitin carboxyl-terminal hydrolase 1 gene; PfUGT: Plasmodium falciparum UDP-galactose transporter; PND: pyronaridine; PPQ: piperaquine; QN: quinine; SNP: single nucleotide polymorphism; WHO: World Health Organization.

\section{Acknowledgements}

The authors thank the patients and the staff of the Hôpital Principal de Dakar and of the hospitals of the French National Reference Centre for Imported

Malaria network 
French National Reference Centre for Imported Malaria Study Group: V Augis (Hôpital Pellegrin, Bordeaux), D Basset (Centre Hospitalier Universitaire de Montpellier, Montpellier), P Bastien (Centre Hospitalier Universitaire de Montpellier, Montpellier), F Benoit-Vical (Centre Hospitalier Universitaire de Rangueil, Toulouse), A Berry (Centre Hospitalier Universitaire de Rangueil, Toulouse), P Brouqui (Institut Hospitalo-Universitaire Méditerranée Infection, Marseille), M Cividin (Centre Hospitalier du Pays d'Aix, Aix en Provence), P Delaunay (Centre Hospitalier Universitaire de I'Archet, Nice), L Delhaes (Hôpital Pellegrin, Bordeaux), M Drancourt (Institut Hospitalo-Universitaire Méditerranée Infection, Marseille), T Gaillard (Hôpital d'Instruction des Armées Saint-Anne, Toulon), A Genin (Centre Hospitalier du Pays d'Aix, Aix en Provence), E Garnotel (Hôpital d'Instruction des Armées Laveran, Marseille), E Javelle (Hôpital d'Instruction des Armées Laveran, Marseille), C L'Ollivier (Institut Hospitalo-Universitaire Méditerranée Infection, Marseille), M Leveque (Centre Hospitalier Universitaire de Montpellier, Montpellier), D Malvy (Hôpital Pellegrin, Bordeaux), P Marty (Centre Hospitalier Universitaire de I'Archet, Nice), M Mechain (Hôpital Pellegrin, Bordeaux), G Ménard (Hôpital d'Instruction des Armées Saint-Anne, Toulon), P Millet (Hôpital Pellegrin, Bordeaux), P Minodier (Hôpital Nord, Marseille), A Mottard (Hôpital de Fréjus-Saint Raphael, Fréjus), P Parola (Institut Hospitalo-Universitaire Méditerranée Infection, Marseille), R Piarroux (Hôpital la Timone, Marseille), C Pomares-Estran (Centre Hospitalier Universitaire de l'Archet, Nice), M-C Receveur (Hôpital Pellegrin, Bordeaux), A Robin (Centre Hospitalier du Pays d'Aix, Aix en Provence), E Sappa (Centre Hospitalier du Pays d'Aix, Aix en Provence), H Savini (Hôpital d'Instruction des Armées Laveran, Marseille), F Simon (Hôpital d'Instruction des Armées Laveran, Marseille), Y Sterkers (Centre Hospitalier Universitaire de Montpellier, Montpellier), C Surcouf (Hôpital d'Instruction des Armées Laveran, Marseille), E Varlet (Centre Hospitalier Universitaire de Montpellier, Montpellier), A Wolff (Hôpital d'Instruction des Armées Laveran, Marseille).

\section{Authors' contributions}

FTF, MGR, MG, and MM carried out the molecular studies. JM, RA, NB, MWG, SD and $\mathrm{BP}$ carried out the ex vivo evaluation of anti-malarial drug susceptibility. $\mathrm{BP}, \mathrm{RB}, \mathrm{BF}$ and MM conceived and coordinated the study. FTF, MGR, MM and BP analysed the data and drafted the manuscript. All authors read and approved the final manuscript.

\section{Funding}

This research was supported by the Délégation Générale pour l'Armement (Grant No. PDH-2-NRBC-4-B-4104), the Schéma directeur Paludisme Etat Major des Armées Françaises (Grant LR 607), by the Ministère des Affaires Etrangères and by the French Institute for Public Health Surveillance (Santé Publique France, Grant CNR paludisme). Francis T Foguim was supported by a scholarship from the Foundation Méditerranée Infection.

\section{Availability of data and materials}

The datasets analysed in this study are available from the corresponding author on reasonable request.

\section{Ethics approval and consent to participate}

Bio-banking of human clinical samples used for malaria diagnostics and secondary uses for scientific purposes is possible as long as the corresponding patients are informed and have not indicated any objections. This requirement was fulfilled here by giving verbal information to the patients, and no immediate or delayed patient opposition was reported to the hospital clinicians. Verbal consent was obtained from all the patients or their parents/guardians before blood collection in Dakar. The ethical committee of the Hôpital Principal de Dakar approved the study. Informed consent was not required for this study because the sampling procedures and testing are part of the French national recommendations for the care and surveillance of malaria.

\section{Consent for publication}

Not applicable.

\section{Competing interests}

The authors declare that they have no competing interests.

\section{Author details}

${ }^{1}$ Unité Parasitologie et Entomologie, Département de Microbiologie et de maladies infectieuses, Institut de recherche biomédicale des armées, IHU Méditerranée Infection, 19-21 Boulevard Jean Moulin, 13005 Marseille, France.
${ }^{2}$ IRD, SSA, AP-HM, VITROME, Aix Marseille Université, Marseille, France. ${ }^{3}$ IHU Méditerranée Infection, Marseille, France. ${ }^{4}$ Fédération des laboratoires, Hôpital Principal de Dakar, Dakar, Senegal. ${ }^{5}$ Centre national de référence du Paludisme, Marseille, France. ${ }^{6}$ Laboratoire d'analyses médicales, Institut Pasteur de Dakar, Dakar, Senegal.

Received: 22 March 2019 Accepted: 17 August 2019

Published online: 28 August 2019

References

1. WHO. Guidelines for the treatment of malaria. 3rd ed. Geneva: World Health Organization; 2015.

2. WHO. World malaria report 2018. Geneva: World Health Organization; 2018.

3. Nosten F, White NJ. Artemisinin-based combination treatment of falciparum malaria. Am J Trop Med Hyg. 2007;77:181-92.

4. Dondorp AM, Nosten F, Yi P, Das D, Phyo AP, Tarning J, et al. Artemisinin resistance in Plasmodium falciparum malaria. N Engl J Med. 2009;361:455-67.

5. Ashley EA, Dhorda M, Fairhurst RM, Amaratunga C, Lim P, Suon S, et al. Spread of artemisinin resistance in Plasmodium falciparum malaria. N Engl J Med. 2015:371:411-23.

6. Slater HC, Griffin J, Ghani A, Okell L. Assessing the potential impact of artemisinin and partner drug resistance in sub-Saharan Africa. Malar J. 2016;15:10

7. Parobek CM, Parr JB, Brazeau NF, Lon C, Chaorattanakawee S, Gosi P, et al. Partner-drug resistance and population substructuring of artemisininresistant Plasmodium falciparum in Cambodia. Genome Biol Evol. 2017:9:1673-86.

8. Ariey F, Witkowski B, Amaratunga C, Beghain J, Langlois A, Khim N, et al. A molecular marker of artemisinin-resistant Plasmodium falciparum malaria. Nature. 2014;505:50-5.

9. Ménard D, Khim N, Beghain J, Adegnika AA, Shafiul-Alam M, Amodu O, et al. A worldwide map of Plasmodium falciparum K13-propeller polymorphisms. N Engl J Med. 2016;374:2453-64.

10. Mukherjee A, Bopp S, Magistrado P, Wong W, Daniels R, Demas A, et al. Artemisinin resistance without pfkelch 13 mutations in Plasmodium falciparum isolates from Cambodia. Malar J. 2017:16:195.

11. Plucinski MM, Talundzic E, Morton L, Dimbu PR, Macaia AP, Fortes F, et al. Efficacy of artemether-lumefantrine and dihydroartemisinin-piperaquine for treatment of uncomplicated malaria in children in Zaire and Uige Provinces, Angola. Antimicrob Agents Chemother. 2015;59:437-43.

12. Dieye $B$, Affara $M$, Sangare $L$, Joof $F$, Ndiaye $Y D$, Gomis JF, et al. West Africa international centers of excellence for malaria research: drug resistance patterns to artemether-lumefantrine in Senegal, Mali, and the Gambia. Am J Trop Med Hyg. 2016;95:1054-60.

13. Plucinski MM, Dimbu PR, Macaia AP, Ferreira CM, Samutondo C, Quivinja J, et al. Efficacy of artemether-lumefantrine, artesunate-amodiaquine, and dihydroartemisinin-piperaquine for treatment of uncomplicated Plasmodium falciparum malaria in Angola, 2015. Malar J. 2017;16:62.

14. Sutherland CJ, Lansdell P, Sanders M, Muwanguzi J, van Schalkwyk DA, Kaur $\mathrm{H}$, et al. Pfk13-independent treatment failure in four imported cases of Plasmodium falciparum malaria treated with artemetherlumefantrine in the United Kingdom. Antimicrob Agents Chemother. 2017:61:e02382-16.

15. Madamet M, Kounta MB, Wade KA, Lo G, Diawara S, Fall M, et al. Absence of association between polymorphisms in the $\mathrm{K} 13$ gene and the presence of Plasmodium falciparum parasites at day 3 after treatment with artemisinin derivatives in Senegal. Int J Antimicrob Agents. 2017:49:754-6.

16. Demas AR, Sharma Al, Wong W, Early AM, Redmond S, Bopp S, et al Mutations in Plasmodium falciparum actin-binding protein coronin confer reduced artemisinin susceptibility. Proc Nath Acad Sci USA. 2018;115:12799-804.

17. Henriques G, Hallett RL, Beshir KB, Gadalla NB, Johnson RE, Burrow R, et al. Directional selection at the pfmdr1, pfcrt, pfubp 1, and pfap2mu loci of Plasmodium falciparum in Kenyan children treated with ACT. J Infect Dis. 2014:210:2001-8. 
18. Spring MD, Lin JT, Manning JE, Vanachayangkul P, Somethy S, Bun R, et al. Dihydroartemisinin-piperaquine failure associated with a triple mutant including kelch13 C580Y in Cambodia: an observational cohort study. Lancet Infect Dis. 2015;15:683-91.

19. Amaratunga C, Lim P, Suon S, Sreng S, Mao S, Sopha C, et al. Dihydroartemisinin-piperaquine resistance in Plasmodium falciparum malaria in Cambodia: a multisite prospective cohort study. Lancet Infect Dis. 2016;16:357-65.

20. Phuc BQ, Rasmussen C, Duong TT, Dong LT, Loi MA, Ménard D, et al. Treatment failure of dihydroartemisinin/piperaquine for Plasmodium falciparum malaria, Vietnam. Emerg Infect Dis. 2017;23:715-7.

21. Thanh NV, Thuy-Nhien N, Tuyen NT, Tong NT, Nha-Ca NT, Dong LT, et al. Rapid decline in the susceptibility of Plasmodium falciparum to dihydroartemisinin-piperaquine in the south of Vietnam. Malar J. 2017;16:27.

22. Witkowski B, Duru V, Khim N, Ross LS, Saintpierre B, Beghain J, et al. A surrogate marker of piperaquine-resistant Plasmodium falciparum malaria: a phenotype-genotype association study. Lancet Infect Dis. 2017;17:174-83.

23. Amato R, Lim P, Miotto O, Amaratunga C, Dek D, Pearson RD, et al. Genetic markers associated with dihydroartemisinin-piperaquine failure in Plasmodium falciparum malaria in Cambodia: a genotype-phenotype association study. Lancet Infect Dis. 2017;17:164-73.

24. Conrad MD, Mota D, Foster M, Tukwasibwe S, Legac J, Tumwebaze P, et al. Impact of intermittent preventive treatment during pregnancy on Plasmodium falciparum drug resistance-mediating polymorphisms in Uganda. J Infect Dis. 2017;216:1008-17.

25. Rasmussen SA, Ceja FG, Conrad MD, Tumwebaze PK, Byaruhanga O, Katairo T, et al. Changing antimalarial drug sensitivities in Uganda. Antimicrob Agents Chemother. 2017;61:e01516-17.

26. Kakolwa MA, Mahende MK, Ishengoma DS, Mandara Cl, Ngasala B, Kamugisha E, et al. Efficacy and safety of artemisinin-based combination therapy and molecular markers for artemisinin and piperaquine resistance in Mailand Tanzania. Malar J. 2018;17:369.

27. Robert MG, Foguim Tsombeng F, Gendrot M, Mosnier J, Amalvict R, Benoit N, et al. Absence of high level of duplication of the plasmepsin 2 gene in Africa. Antimicrob Agents Chemother. 2018;62:e00374-18.

28. Robert MG, Foguim Tsombeng F, Gendrot M, Diawara S, Madamet M, Kounta MB, et al. Baseline ex vivo and molecular responses of Plasmodium falciparum isolates to piperaquine before implementation of dihydroartemisinin-piperaquine in Senegal. Antimicrob Agents Chemother. 2019;63:e02445-18.

29. Ross LS, Dhingra SK, Mok S, Yeo T, Wicht KJ, Kümpornsin K, Takala-Harrison $\mathrm{S}$, et al. Emerging Southeast Asian Pfcrt mutations confer Plasmodium falciparum resistance to the first-line antimalarial piperaquine. Nat Commun. 2018:9:3314.

30. Fidock DA, Nomura T, Talley AK, Cooper RA, Dzekunov SM, Ferdig MT, et al. Mutations in the P. falciparum digestive vacuole transmembrane protein PfCRT and evidence for their role in chloroquine resistance. Mol Cell. 2000;6:861-71.

31. Pradines B, Parquet V, Orlandi-Pradines E. ABC transporters in Plasmodium and their involvement in resistance to antimalarial drugs. In: Ponte-Sucre A, editor. ABC transporters in microorganisms. Wymondham: Caister Academic Press; 2009. p. 113-28.

32. Veiga MI, Dhingra SK, Henrich PP, Straimer J, Gnägig N, Uhlemann AC, et al. Globally prevalent PfMDR1 mutations modulate Plasmodium falciparum susceptibility to artemisinin-based combination therapies. Nat Commun. 2016;7:11553.

33. Sidhu AB, Valderramos SG, Fidock DA. Pfmdr1 mutations contribute to quinine resistance and enhance mefloquine and artemisinin sensitivity in Plasmodium falciparum. Mol Microbiol. 2005;57:13-926.

34. Price RN, Uhlemann AC, Brockman A, McGready R, Ashley E, Phaipun $L$, et al. Mefloquine resistance in Plasmodium falciparum and increased pfmdr1 gene copy number. Lancet. 2004;364:438-47.

35. Nankabirwa Jl, Conrad MD, Legac J, Tukwasibwe S, Tumwebaze P, Wandera $\mathrm{B}$, et al. Intermittent preventive treatment with dihydroartemisinin-piperaquine in Ugandan schoolchildren selects for Plasmodium falciparum transporter polymorphisms that modify drug sensitivity. Antimicrob Agents Chemother. 2016;60:5649-54.
36. Martin RE, Henry RI, Abbey JL, Clements JD, Kirk K. The 'permeome' of malaria parasite: an overview of the membrane transport protein of Plasmodium falciparum. Genome Biol. 2015;6:R26.

37. Yan N. Structural biology of the major facilitator superfamily transporters. Annu Rev Biophys. 2015;44:257-83.

38. Lim MY, LaMonte G, Lee MC, Reimer C, Tan BH, Corey V, et al. UDPgalactose and acetyl-CoA transporters as Plasmodium multidrug resistance genes. Nat Microbiol. 2016;19:16166.

39. Kuhen KL, Chatterjee AK, Rottmann M, Gagaring K, Borboa R, Buenviaje $J$, et al. KAF156 is an antimalarial clinical candidate with potential for use in prophylaxis, treatment, and prevention of disease transmission. Antimicrob Agents Chemother. 2014;58:5060-7.

40. White NJ, Duong TT, Uthaisin C, Nosten F, Phyo AP, Hanboonkunupakam B, et al. Antimalarial activity of KAF156 in falciparum and vivax malaria. N Engl J Med. 2016;375:1152-60.

41. Meister S, Plouffe DM, Kuhen KL, Bonamy GMC, Wu T, Whitney Barnes $\mathrm{S}$, et al. Imaging of Plasmodium liver stages to drive next-generation antimalarial drug discovery. Science. 2011;334:1372-7.

42. LaMonte G, Lim MY, Wree M, Reimer C, Nachon M, Corey V, et al. Mutations in the Plasmodium falciparum cyclic amine resistance locus (PfCARL) confer multidrug resistance. Mbio. 2016;7:e00696-16.

43. Magistrado PA, Corey VC, Lukens AK, LaMonte G, Sasaki E, Meister S, et al. Plasmodium falciparum cyclic amine resistance locus (PfCARL), a resistance mechanism for two distinct compounds classes. ASC Infect Dis. 2016;2:816-26.

44. Jonikas MC, Collins SR, Denic V, Oh E, Quan EM, Schmid V, et al. Comprehensive characterization of genes required for protein folding in the endoplasmic reticulum. Science. 2009;323:1693-7.

45. Boussaroque A, Fall B, Madamet M, Wade KA, Fall M, Nakoulima A, et al. Prevalence of anti-malarial resistance gens in Dakar, Senegal from 2013 to 2014. Malar J. 2016:15:347.

46. Fall B, Madamet M, Camara C, Amalvict R, Fall M, Nakoulima A, et al. Plasmodium falciparum in vitro resistance to monodesethylamodiaquine, Dakar, Senegal, 2014. Emerg Infect Dis. 2016;22:841-5.

47. Diawara S, Madamet M, Kounta MB, Lo G, Wade KA, Nakoulima A, et al. Confirmation of Plasmodium falciparum in vitro resistance to monodesethylamodiaquine and chloroquine in Dakar, Senegal, in 2015. Malar J. 2017;16:118

48. Wurtz N, Fall B, Bui K, Pascual A, Fall M, Camara C, et al. Pfhrp2 and pfhrp3 polymorphisms in Plasmodium falciparum isolates from Dakar. Senegal: impact on rapid malaria diagnostic tests. Malar J. 2013;12:34.

49. Pascual A, Basco LK, Amalvict R, Travers D, Rogier C, Pradines B. Use of the atmospheric generators for capnophilic bacteria Genbag- $\mathrm{CO}_{2}$ for the evaluation of in vitro Plasmodium falciparum susceptibility to standard anti-malarial drugs. Malar J. 2011;10:8.

50. Pradines B, Bertaux L, Pomares C, Delaunay P, Marty P. Reduced in vitro susceptibility to artemisinin derivatives associated with multi-resistance in a traveler returning from South-East Asia. Malar J. 2011;10:268.

51. Pascual A, Madamet M, Briolant S, Gaillard T, Amalvict R, Benoit N, et al. Multinormal in vitro distribution of Plasmodium falciparum susceptibility to piperaquine and pyronaridine. Malar J. 2015;14:49.

52. Fall B, Camara C, Fall M, Nakoulima A, Dionne P, Diatta B, et al. Plasmodium falciparum susceptibility to standard and potential anti-malarial drugs in Dakar, Senegal, during the 2013-2014 malaria season. Malar J. 2015;14:60.

53. Bogreau H, Renaud F, Bouchiba H, Durand P, Assi SB, Henry MC, et al. Genetic diversity and structure of African Plasmodium falciparum populations in urban and rural areas. Am J Trop Med Hyg. 2006;74:953-9.

54. Henry M, Diallo I, Bordes J, Ka S, Pradines B, Diatta B, et al. Urban malaria in Dakar, Senegal: chemosusceptibility and genetic diversity of Plasmodium falciparum isolates. Am J Trop Med Hyg. 2006;75:146-51.

55. Duru V, Khim N, Leang R, Kim S, Domergue A, Kloeung N, et al. Plasmodium falciparum dihydroartemisinin-piperaquine failures in Cambodia are associated with mutant $\mathrm{K} 13$ parasites presenting high survival rates in novel piperaquine in vitro assays: retrospective and prospective investigations. BMC Med. 2015;13:305.

56. Basco LK. Field application of in vitro assays for the sensitivity of human malaria parasites to antimalarial drugs. Geneva: World health Organization; 2007. p. 69-71. 
57. Pradines B, Spiegel A, Rogier C, Tall A, Mosnier J, Fusai T, et al. Antibiotics for prophylaxis of Plasmodium falciparum infections: in vitro activity of doxycycline against Senegalese isolates. Am J Trop Med Hyg. 2000;62:82-5.

58. Pradines B, Rogier C, Fusai T, Mosnier J, Daries W, Barret E, et al. In vitro activities of antibiotics against Plasmodium falciparum are inhibited by iron. Antimicrob Agents Chemother. 2001;45:1746-50.

59. Briolant S, Parola P, Fusai T, Madamet-Torrentino M, Baret E, Mosnier J, et al. Influence of oxygen on asexual blood cycle and susceptibilily of Plasmodium falciparum to chloroquine: requirement of a standardized in vitro assay. Malar J. 2007;6:44.
60. Wein S, Maynadier M, Tran Van Ba C, Cerdan R, Peyrottes S, Fraisse L, et al. Reliability of antimalarial sensitivity tests depends on drug mechanism of action. J Clin Microbiol. 2010;48:1651-60.

\section{Publisher's Note}

Springer Nature remains neutral with regard to jurisdictional claims in published maps and institutional affiliations.
Ready to submit your research? Choose BMC and benefit from:

- fast, convenient online submission

- thorough peer review by experienced researchers in your field

- rapid publication on acceptance

- support for research data, including large and complex data types

- gold Open Access which fosters wider collaboration and increased citations

- maximum visibility for your research: over 100M website views per year

At BMC, research is always in progress.

Learn more biomedcentral.com/submissions 